\title{
How to give a consultation and how to get a consultation
}

\author{
Alun D. Ackery, MD, $\mathrm{MSc}^{* \dagger}$; Jeremy W. Adams, MD*; Steven C. Brooks, MD, MHSc ${ }^{*}{ }^{*}$; \\ Allan S. Detsky, MD, $\mathrm{PhD}^{11 /}$
}

The interaction between emergency physicians and consultants is an important component of patient care. ${ }^{1-3}$ In this commentary, we offer suggestions to both physicians who ask for consultations and consultants who receive those requests. This advice applies mostly to medical students and junior residents who are just learning their way around the emergency department and who are susceptible to both the good and the bad habits of their supervisors. For those longtime workers in the "emergency trenches," we hope that this advice will give a new perspective to better relationships with your colleagues.

\section{THE PERSPECTIVE OF THE EMERGENCY PHYSICIAN}

Patients seen in emergency departments tend to fall into four categories: 1) those who can be safely discharged after assessment by an emergency physician, 2) those with a clear diagnosis of a medical condition that requires admission to the hospital, 3) those without a clear diagnosis after assessment who are not appropriate for discharge, and 4) those with social circumstances that preclude safe discharge. Most of the problem interactions between consultants and emergency physicians occur around categories 3 and 4 .

In observing emergency physicians practice, it sometimes appears that, in an effort to get what the patient needs, they "sell" patient stories to a consultant service. This may be a "tough sell" for patients in the grey zone (categories 3 and 4) because their problems may not be core to the specialty practice of the consultant. It sometimes seems that no one wants to take the lead in caring for these people. Here are some tips to help the emergency physician manage this interaction:

1. Learn people's names. When the consultant answers the telephone (whether a staff member or a resident), ask for his or her name and give yours. Try to interact with individuals face to face and use eye contact and good humour in doing so. Listen to your consultant's concerns and address them honestly. This kind of collegial approach builds rapport; people know they will meet again and remember the interactions.

2. Clearly state what you are requesting from the consultant; your first remarks should reflect whether you are asking a question or for a consultation. State your working diagnosis and specify whether you are asking for advice, ongoing management, or the disposition of the patient (i.e., admission or followup care.) Make your requests brief: allow the consultant to ask additional questions if needed rather than flooding him or her with details initially.

From the *Department of Medicine, University of Toronto; †Division of Emergency Medicine, University of Toronto; $¥$ Keenan Research Centre, Li Ka Shing Knowledge Institute, St. Michael's Hospital; §Department of Emergency Services and the Sunnybrook Research Institute, Sunnybrook Health Sciences Centre; IIDepartments of Health Policy Management and Evaluation, University of Toronto; and $\uparrow$ Departments of Medicine, Mount Sinai Hospital and University Health Network, Toronto, ON.

Correspondence to: Dr. Allan S. Detsky, Mount Sinai Hospital, 600 University Avenue, Suite 429, Toronto, ON M5G 1X5; adetsky@mtsinai.on.ca. Submitted January 8, 2010; Revised April 6, 2010; Accepted May 15, 2010

This article has been peer reviewed.

(C) Canadian Association of Emergency Physicians

CJEM 2011;13(3):169-171

DOI 10.2310/8000.2011.110268

Keywords: communication, obtaining consultations, quality improvement 
3. Be honest. If you are asking for a consultation because it is a "social admission" owing to poor support, noncompliance, or pressure from the family, make that explicit in your request. Do not feel you have to fabricate a medical issue to justify the consultation. Doing so will annoy your consultant when he or she recognizes the truth. Patient safety is a legitimate concern because of the home social issues at hand. In addition, most specialists understand the difficulty managing patients with acute exacerbations of chronic pain and the occasional need to admit them for symptom control rather than diagnosis.

4. Have empathy for consultants. We have all faced nights when we are bombarded with patient care. In these circumstances, make it clear that you understand his or her predicament and offer to help by ordering tests or observing the patient until he or she has time. Anticipate your consultant's needs. If possible, obtain special equipment, medications, or rooms. Ask consultants who anticipate delays simple questions that will have an impact on patient needs. (Can the patient eat or drink? When will the consultation likely be completed? When will the follow-up appointment occur?)

5. Know the medical disposition algorithms. Some services have complex algorithms, and some have simpler referral patterns. Work with your departments to establish guidelines for caring for patients who frequently have special needs. It is important to understand that these are guidelines, and sometimes the best interest of the patient requires flexibility.

6. Do not lose your cool. If the consultant refuses to see a patient, do not lose your temper, but simply let him or her know that you have noted that refusal. At this point, the best strategy is to consult another staff physician or colleague, who can interact with the initial consulting service. (That is why it is important to know people's names, both residents and staff.) It may be necessary to contact the department chair or chief of medical staff if patient safety is a legitimate concern. Consider admitting patients to alternative services if there are no other options or keeping patients in the emergency department until other consultant staff are available for advice. Avoid heated discussions in areas where being overheard will disparage your clinical care or institution. If you consider a consultant's recommendations to be possibly harmful, you have an obligation to discuss your concerns with the patient (or patient's family).

7. Be active in follow-up. Consultants like to know that emergency physicians are interested in the outcomes of the patients they have seen. Make a point of asking what happened, not just for the interesting or classic cases but also for the difficult patients. This behaviour will reap rewards when you ask for consultations in the future.

\section{PERSPECTIVE OF THE CONSULTING SERVICE}

All specialty services hope to get the kinds of cases that epitomize their specialty. Surgeons like referrals that lead to operations. Internists like interesting diagnostic problems with therapies that actually help patients. Everyone likes patients and families who are easy to deal with and cases that teach the resident something. Everyone also likes to sleep when they are on call. Unfortunately, life does not always work out that way. Here are some tips for colleagues on a consulting service:

1. Listen carefully to the referring physician. This sounds simple, but we all have a tendency to tune out when the consultation begins with "Sorry, but this is not a great referral." Ask questions of the consulting physician about what he or she is specifically looking for in the consultation. (This point is the reciprocal of point 2 in the previous section.) Be accepting of the truth.

2. Reassess with fresh eyes. Do not assume that the diagnosis of the person requesting the consultation is correct. Taking a careful history from the patient is critically important, especially in those with nonspecific complaints. We are often surprised that vague complaints over time turn into very specific stories that lead to interesting diagnoses. In the same vein, if you are reluctant to accept a referral, it is always best to see the patient personally before telling the emergency physician that you have nothing to offer.

3. Be nice. If you know that a patient will be coming to your service for sure, accept him or her with open arms. There is no point in taking out your frustration or hostility on the referring physician or the patient. After all, they are our "clients" and require our help. When you feel most frustrated, step back, take a deep breath, and try to remember your medical school application essay. Do not make 
enemies. Remember, being right does not necessarily mean that you will prevail.

4. Ask for help. If you feel overwhelmed, seriously fatigued, or physically ill, you have the right to inform the people sending you consultations. Almost all patients can be held until the next person starts his or her shift. No one will react negatively if you say that you have simply reached your limit. (This echoes point 4 of the preceding section.)

\section{THE BOTTOM LINE}

Emergency physicians sometimes need help with the patients they see. We are all pressured with managing multiple tasks on any given day. We all want to improve the timeliness of care in the emergency department. These pressures can sometimes create a situation where it seems that colleagues are starting a conversation with "How can't I help you?" However, one must remember that our core business is helping people. In times of conflict and stress, a recommended approach would be to ask, "What is in the best interest of the patient?" Once you answer that question, it will be clear what you should do next.

Competing interests: None declared.

\section{REFERENCES}

1. Eisenberg EM, Murphy AG, Sutcliffe KM, et al. Communication in emergency medicine: implications for patient safety. Commun Monogr 2005;72:390-413, doi:10.1080/ 03637750500322602 .

2. Horwitz LI, Meredith T, Schurr JD, et al. Dropping the baton: a qualitative analysis of failures during the transition from emergency departments to inpatient care. Ann Emerg Med 2009;53:701-10, doi:10.1016/j.annemergmed.2008.05. $\underline{007}$.

3. Kripalani S, LeFevre F, Phillips CO, et al. Deficits in communication and information transfer between hospitalbased and primary care physicians: implications for patient safety and continuity of care. 7AMA 2007;297:831-41, doi:10.1001/jama.297.8.831. 